\title{
Pedagogical Strategies For Incorporating Behavioral Finance Concepts In Investment Courses
}

Michael Adams, (E-mail: madams1@ju.edu), Jacksonville University Terry Mullins, (E-mail: tmullin@ju.edu), Jacksonville University

Barry Thornton, (E-mail: bthornt@ju.edu), Jacksonville University

\begin{abstract}
The traditional approach to teaching a course in investments is predicated upon the efficient market hypothesis, modern portfolio theory, and the assumption that decision-makers are rational, wealth optimizing entities. Recent developments in the arena of behavioral finance (BF) have raised questions about this approach. Although the idea of efficient markets is widely accepted in academic circles, financial markets often fail to behave as predicted by the theory. For the teacher of undergraduate investments, these divergent views create significant pedagogical challenges and opportunities. BF has particular implications for investing in financial markets, where the faith in rational behavior is perhaps the greatest. This paper identifies alternative strategies for dealing with these issues in the classroom.
\end{abstract}

\section{THE TRADITIONAL APPROACH TO TEACHING INVESTMENTS}

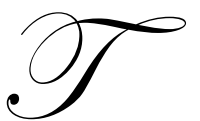

he typical instructor of an investments class will attempt to instill the tenets of modern finance in all of his or her students. Classical finance theory assumes that investors are rational and attempts to explain how they should behave in order to maximize their wealth. Investment theory generally posits that the stock market is efficient since all information is rapidly reflected in security prices and investors act rationally to maximize their self interest and wealth creation. Capital markets offer the real world's best approximation to the idealized price auction of a "perfect" market envisioned in economic theory because information is spread quickly at low cost to rational wealth maximizers who correctly use the information in an attempt to make a profit and thus collectively determine underlying asset values. With that as a backdrop, financial theory has provided some powerful analytical tools for investors. These ideas have brought us such theoretical models as the arbitrage pricing theory (APT), modern portfolio theory (MPT), the Fama-French three factor model (FF3F), and the option pricing model (OPM).

The traditional approach to teaching a course in investments generally dismisses the idea that psychology is an important determinate of financial decision-making. From the first lecture to the last class, the standard propositions set forth in a typical investments course are firmly rooted in the efficient markets hypothesis (EMH). An efficient market is one where information is assumed to be widely and inexpensively available to all investors. In this context, efficiency implies that markets are reasonably accurate collectors and assessors of information. Since it is assumed that individuals are rational and act in their own economic self-interest, the EMH posits that stock prices will usually quickly reflect all publicly available information. These assumptions of EMH borrow heavily from longestablished microeconomic theory.

Most college investment courses are generally organized around this basic construct: that security markets are nearly efficient, meaning that most securities are usually priced appropriately, given their degree of risk and return attributes. In essence, there are "no free lunches" found in financial markets as competitive as the stock market. This simple observation is, however, remarkably powerful in its implications for the design and implementation of investment strategies. While the degree of market efficiency is, and perhaps always will be, a source of disagreement 
between academicians and investment practices, classroom instruction throughout the semester should convey a large dose of healthy criticism concerning much of the conventional wisdom.

Modern investment theory assumes a status quo of the following conditions: (1) markets are in equilibrium; (2) they are competitive, i.e., there are a large number of small buyers and sellers, each of whom is unable to influence the market price; (3) market participants have the goal of utility maximization; and (4) all investors have equal access to the same information set. However, recent empirical research has demonstrated that financial markets are not fully efficient and the capital market inefficiencies (anomalies of prices and returns) are systematic due to investor's cognitive biases. These results are the antithesis of the EMH. In its purest sense, BF is simply the study of psychological forces, as opposed to market forces, that drive stock prices away from their fundamental values by investors who have emotions and are systematically fraught with mental heuristics (mental errors) and systematically deviate from normative theory.

\section{BF APPROACH TO TEACHING INVESTMENTS}

Behavioral finance studies how investors actually behave when making financial decisions. Therein lies the fundamental difference between neo-classical finance and behavioral finance. Specifically, it is the study of how psychology affects individual financial decision making and the impact this has on the financial markets. A more appropriate designation for BF might be called "cognitive finance". Some advocates of BF take an informal approach, suggesting that the paradigm can be distilled down to a simple mantra of "embracing the irrationality of investors". $\mathrm{BF}$ is an attempt to augment the normative explanatory power of traditional finance by providing it with more realistic psychological foundations.

There is a growing body of empirical research that indicates financial markets often fail to behave as they should if trading were truly dominated by the fully rational investor that is assumed in the classical theory. Despite empirical evidence that the stock market is semi-strong efficient, there are many studies documenting long-term historical anomalies in the stock market that would seem to contradict the validity of the EMH. While the existence of these market anomalies is generally well accepted, the question of whether or not investors can exploit them in systematic fashion to earn superior returns in the future is less clear. "A market is efficient with respect to a particular set of information if it is impossible to make abnormal profits (other than by chance) by using this set of information to formulate buying and selling decisions" (Sharpe 1984). The only rational investment strategy consistent with the concept of efficient markets is indexing using Electronic Traded Funds (ETFs). The conundrum is, however, if everyone indexes, the markets will no longer be efficient

BF still remains at the fringes of modern financial theory, perhaps because there is still no behavioral equivalent of the CAPM, a technique rapidly being replaced in academia, but still widely employed in practice. BF looks at investor preference functions in an intuitive fashion as opposed classical investment theory's mathematical closed-form model solutions. The goal of BF is to make predictions that are more consistent with the empirically observed outcomes. BF is an attempt to explain what causes some of the stock market anomalies that have been observed and reported in the finance literature, such as the calendar effect, weather, the weekend effect, small firm effect, closed end mutual fund paradox, and momentum strategy.

At the root of the pedagogical differences is the notion that BF rejects the EMH as envisioned by Fama, which for decades has been the standard finance valuation paradigm, both in assumptions underlying the model and in the practical applications. Eugene Fama (1970) framed the definition of EMH and identified the three variants of it: (1) superior or private information (strong-form EMH); (2) superior cognitive processing of information (semi-strong EMH); and (3) the ability to interpret charts and patterns to select investments (weak-form EMH). Fama (1991) stated “...market efficiency per se is not testable. It must be tested jointly with some model of market equilibrium, an asset pricing model." The EMH, similar to all economic theories, makes simplifying assumptions about both market conditions and the behavioral objectives and actions underlying the model. At the core, BF questions whether the behavioral assumptions underlying the EMH are true or even semi-valid. 
The efficient market hypothesis gained additional support with the publication of Burton Malkiel's book, "A Random Walk down Wall Street," where he observed that changes in stock prices follow a random walk. Dr. Malkiel's thesis is since information is received randomly, stock prices should be time series independent. Since no individual investor can predict when positive or negative information is going to be received in the market, it is impossible to detect a pattern in historical stock prices and profit by exploiting those patterns. The tautology is if stock prices reflect all known information, then only unpredictable unknown information is left, and ergo price changes must be randomly distributed.

In contrast to the "wealth-maximizer" model of investor behavior assumed in classical theory, BF suggests that when forming expectations, investors often employ: (1) a limited information set, and (2) flawed heuristics for processing the information. BF has evolved from attempts to better understand and explain how emotions and cognitive errors influence investors and the decision-making process. BF researchers believe that the study of psychology can shed considerable insight into the inefficiency of financial markets as well as provide a behavioral explanation for the many stock market anomalies, market bubbles, and crashes noted in the financial literature. New and better explanations for the non-rational aspects of investor decision making behavior leans heavily on the psychology literature rather than that of economics and finance.

Classical economic theory assumes that people make good use of the information that is available to them and then act in an unbiased manner. Empirical research has demonstrated, however, that many investors do not act as this theory assumes they will. They tend to be overly optimistic and overconfident. As a result, their actual success rate is typically well below their lofty expectations. Further evidence is provided by the research of Drs. Daniel Kahneman and Vernon Smith, recipients of the Nobel Prize in economics in 2003. They posited that investors are not systematically rational, as traditional economic theory asserts, and that they often make financial decisions for emotional reasons, ergo basing their investment decisions on cognitive errors.

The assumption that investors are self-interested wealth maximizers means that they form unbiased expectations regarding the future and then buy and sell at prices which they believe will maximize the future value of their portfolios. This is generally considered naïve by most advocates of BF which considers how investors form expectations regarding the future and how those expectations are reflected in the prices of securities. Cognitive errors can cause investors to form biased expectations regarding the future (noise traders) that, in turn, can result in securities being either over- or under-valued for an extended period of time. Arbitrage opportunities are generally not applicable because of these noise traders and their effect on long-term equilibrium prices.

EMH posits that irrational investors' trades are uncorrelated and will have a tendency to cancel each other out. However, BF argues that these noise traders make the same errors in a systematic fashion and thus the actions of arbitrageurs will not bring prices back to fundamental values at least in the short run. For example in a seminal study of market efficiency, Fama and French demonstrated that buying low price-to-earnings (p/e) or price-to-book (p/b) stocks, a classic value investing strategy, appears to yield superior long-term results. (Fama \& French, 1995). For illustration purposes, suppose the FF three-factor model generates excess returns (alphas). Alpha can be defined as the difference between a portfolio's risk-adjusted return and the return for an appropriate benchmark portfolio. In this sense, alpha is the ability to form expectations that are superior to the market's expectations. If the majority of investors used a single-factor model (CAPM) to process the information and derive market values, a security could remain over- or under-valued for an extended period of time. In this case the investors' expectations might be unbiased, but they would not be as accurate as the expectations of an individual investor using the FF three-factor model.

\section{BEHAVIORAL BIASES AND COGNITIVE ERRORS}

It is important to note that we are not dealing with fully irrational behavior, but rather with degrees of irrational behavior or biases. Two broad categories of behavioral biases are found in the literature: (1) investor behavior where the goal is not true wealth maximization; and (2) heuristic biases and/or systematic mistakes. 
The central tenet of BF is that practitioners systematically commit cognitive errors because they rely on simple heuristics (rules of thumb) or the improper use of statistical models. Moreover, it is believed that investor's perceptions of risk and return are greatly influenced by how investment decisions are framed. These cognitive errors and decision frames affect how prices are established in the market and tend to make it less efficient than previously assumed. Some examples of heuristics and investor mistakes include but are not limited to the following:

\section{Availability Bias}

This is the tendency for investors to base investment decisions on the most readily available information. The availability heuristic suggests that investors judge the probabilities of future events primarily predicated upon how easy the event is to remember. This availability bias also contributes to further biases, such as "hindsight bias."

\section{Overconfidence And Excessive Optimism}

Increasing investor levels of confidence frequently show very little or no correlation to greater success. People have a propensity to be overconfident in their own abilities, and investors and analysts tend to be particularly overconfident in areas in which they have some knowledge. For instance, studies show that men consistently overestimate their own abilities in many areas including athletic skills, ability to get along with others, and their trading prowess. Money managers, advisors, and investors are consistently overconfident in their ability to outperform the market. Unfortunately, there are many empirical studies that clearly demonstrate the majority fail to consistently beat the performance of a market index and very few even match the performance of the market. Albeit, there are some legendary investors who consistently beat the market such as Warren Buffet, Peter Lynch, and George Soros, one could name them all on one hand; they are exceptions to the EMH rubric.

\section{Anchoring}

Psychologists have documented that the price at which an asset was purchased strongly influences estimates of its future value. For example, home prices are strongly affected by the price at which the real estate was purchased. Even though this is a sunk cost and it is not relevant consideration according to classical finance theory, it appears that many investors behave in this irrational manner.

\section{Self-Attribution And The Illusion Of Control}

Investors have a tendency to attribute success to their skills, while blaming failure on plain bad luck. Investors also often see order where it does not exist and interpret accidental success to be the result of skill. The BF literature is replete with statistical demonstrations that many occurrences of investment successes are really the result of pure chance. Studies of online brokers account indicate that investors, especially males overtrade their accounts on average and produce less return than female traders.

Investors frequently trade on information they believe to be superior and relevant, when in fact it is not, and is already fully discounted by the market. This results in frequent noise trading. Classical investment theory believes that the noise trader's action will tend to cancel each other out, thus the market will always gravitate toward efficiency. On one side of each speculative trade is a participant who believes he or she has superior information and on the other side is another participant who believes his/her information is superior. Yet they can't both be right, since the stock market is a zero sum game. Financial decision making and behavioral biases range from the tendency to believe things because many other investors do (Herd mentality or group think) to confirmation bias or the tendency to search for or interpret market information in a way that confirms one's preconceptions. Some other examples would include the following:

\section{Mental Accounting Bias}

Depending on the source of funds, investors may employ wildly different investment strategies. Funds flowing into a $401 \mathrm{k}$ from payroll deductions are likely to be invested fairly conservatively, while a windfall may be 
invested quite aggressively. An additional point to consider is that investors tend to segregate each investment in order to track gains and losses and periodically reexamine positions. Viewing each investment separately rather than using a portfolio approach limits most investors’ ability to minimize risk and maximize return.

\section{Loss Aversion}

Investors fear losses and work hard to avoid them. Research has shown that the emotional pain associated with a given magnitude of loss is felt approximately $2 \frac{1 / 2}{2}$ times more than a gain of the same magnitude (Tversky \& Kahneman, 1991). Both anecdotal and empirical evidence suggest that loss aversion behavior is more representative of most investors than the standard continuous concave utility function of wealth typically taught in the investment classroom i.e., the marginal utility of wealth is always positive. Lengthening the time one holds an investment can often reduce the probability of experiencing a loss on their investment. In a seminal study of stock market history, the highest return, lowest return and average annual return of the S\&P 500 over various holding periods from 1926 to 2005 were analyzed. It should be noted that as you move from a one-year holding period to a three-year, 10-year, and finally to a 20-year holding period, the number of negative returns experienced goes down. In fact, there's never been a 20-year period with a negative return. The longer you hold an investment, the less chance of experiencing a negative return. Investing for the long-term can help maximize wealth, prevent costly mistakes and lower the downside risk in your portfolio. However, most investors tend to sell their winners early and hold their losers longer because of the loss aversion investment bias. See Exhibit B.

\section{Representativeness}

Many investors have a tendency to over-generalize from small samples or limited personal investment decisions. Such investors when dealing with complex mathematical models with Greek formulae often develop simplistic rules of thumb that have minimal validity when examined critically. For example, the so-called "hot hand fallacy" of basketball players has been discredited by empirical studies, yet most sport fans believe in it. In the world of finance, the conviction that dividend cuts are sure signs of company weakness would fall into this category. Moreover, investors typically give too much weight to recent experience and extrapolate recent trends that are not consistent with long-run averages and statistical odds. Although an investor can have no control over the movement of stock prices, many investors do in fact imagine that they exercise some control over them. Investors, in general, tend to become more optimistic when the market goes up and more pessimistic when the market goes down. As an example, many believe that when high percentages of participants become overly optimistic or pessimistic about the future, it is a signal that the opposite scenario will occur (the classical contrarian’s approach).

\section{Saliency}

Dramatic and emotional events are memorable. When such events occur, particularly if they are rare, investors tend to overestimate the probability of such an event occurring in the future. For example, in a recent study of Japanese investors, when individual investors were queried about the probability of a stock market crash immediately after one occurs, they tended to state a value much higher than the true probability of this event. Moreover, the context in which investment choices are presented greatly influences the decision-making process. In particular, it is possible to overwhelm the investor with choices, resulting in him or her being unable to make any decision.

\section{Context Effect Bias}

The inability to make an investment decision of investable funds is clearly not wealth maximizing behavior on the part of the investor. Even the simple act of making a choice induces a control element bias. For example, people who choose their own lotto numbers believe that they have a better chance of winning than people who play quick picks. Many investors and students think they can time the market by exiting at the peak and re-entering the market at the trough. Many empirical studies of the stock market have concluded that timing short-term to intermediate term market shifts correctly has proved to be nearly impossible. However, not investing when one has investable funds to invest, can be a generally less known form of market timing. By staying out of the market, an 
investor is assuming they can predict the market's near-term results. This is usually based on the recent past, which can be very misleading. Even the simple act of making a choice induces a control element bias. Because returns are often concentrated in very short periods, market timing can be very costly. Looking at returns from 1996-2005 (covering both a bull and bear market) shows that missing the market's top 10 days reduced the total return earned by investors by more than $50 \%$ on a portfolio of stocks, represented by the S\&P 500 index (^SPX). If an investor was out of the market for the top 20 days, their return dropped below the risk free security such as T-bills. And missing the top 30 days - that's 30 days out of 10 years, less than $2 \%$ of the trading day actually produced a negative return. See Exhibit A.

\section{Outcomes Sequence}

The order in which outcomes occur may create the illusion of control. Early positive outcomes give the investor a greater sense of control than early losses do. Investors are greatly influenced by short-term investment results and tend to extrapolate these results into the future.

\section{Disposition Effect}

Many studies have found that fear of regret causes most investors to be predisposed to selling winners too early and riding losers too long. Investors tend to place a higher value on the assets they own relative to those that they don't.

\section{Framing Effect}

Much investor behavior is an outgrowth of prospect theory. This theory describes how people frame and evaluate a decision when it involves uncertainty. Many investors appear to frame their choices in terms of potential gains and losses relative to a specific reference point.

\section{CONCLUSIONS AND IMPLICATIONS FOR TEACHING}

This paper has shown how some of the major assumptions underlying the EMH are being challenged by the findings of new $\mathrm{BF}$ research. However, the insights from $\mathrm{BF}$ will never replace the usefulness of the EMH; they simply provide a more comprehensive understanding of investment decision-making within the framework of the EMH. BF will move more closely to the mainstream of modern investment theory when a behavioral rubric can be created to mimic the certainty equivalent approach in corporate finance.

From a pedagogical point of view, instruction in the undergraduate investments course will continue to be dominated by MPT and the efficient market hypothesis. However, professors can greatly enhance their presentation of classical theory by augmenting their teaching with materials from BF. Adoption of a multidisciplinary approach that incorporates both psychological and speculative aspects to reshape the EMH paradigm provides a fertile field for lively discussion in the classroom.

The advanced investment courses often focus on the selection and management of a portfolio from a rational, analytical perspective. On the most basic level, students may assume that the theory and techniques employed to build and manage investment portfolios and capital asset pricing models are so well understood and proven that the process is rote and mechanical, producing highly predictable results. When Behavioral Finance concepts are introduced into the investments course, students are exposed to paradoxical views of financial decisions that call into question the ability of decision makers to use information efficiently to make financial decisions that are rational. Pedagogically, the introduction of BF concepts into the investments course provides the professor with an opportunity to challenge many of the comfortable, but perhaps incomplete, assumptions about decision making that form the theoretical underpinnings of such courses. Moreover, since BF is a relatively new approach to investing, many senior finance professors responsible for teaching undergraduate investments were not exposed to the principles of BF in their doctorial program's curriculum and can learn to employ new applications of BF pedagogy in their classrooms. 
The integration of BF concepts into the investments course should allow the instructor to accomplish a number of key pedagogical goals. From the instructor's perspective, the contrast between MPT and BF Theory will enhance the classroom experience in the following ways: Briefly,

- $\quad$ Comparing a rival theory to a mainstream theory allows student to better understand the salient features and the assumptions of the established theory.

- $\quad$ By comparing and contrasting competing theories on a point-by-point basis, students will strengthen their critical thinking skills.

- $\quad$ By highlighting the conflict between BF and EMH, the professor will be able to inject drama in a traditionally dry course, stimulate more discussion and examine the underlying assumptions of the typical portfolio manager in a more complex manner.

- $\quad$ As an exposure to BF in the context of the investments curriculum, students will become more aware of their own personal limitations regarding consistently rational decision making.

- When students are taught to look for more than one explanation for the phenomena or market anomaly, they will develop a more sophisticated approach to problem solving.

- $\quad$ The use of BF in the investments course, enables the professor to challenge students to "think outside the box" by developing a more comprehensive theory that encompasses the rival, conflicting models of investor behavior.

- $\quad$ Downside risk is usually dominated by fear and upside potential of a stock is usually guided by greed, two of the strongest emotions. BF incorporates emotions into the investment decision in a more intuitive manner than the classical financial theory. This allows the professor to ask students questions about the impact of emotions on the cognitive decision making and increases student participation in the discussion. For example, many studies have shown that investors with relatively minor emotional impairments have difficulty making decisions and, when they do, they often make poor ones. In fact, in a recent study of accident patients with severe trauma to the head, it was discovered that they made greater returns vis-à-vis a group of cognitive normal investors.

- $\quad$ Investigating market phenomena such as "social investing" can provide a forum to discuss non-wealth maximizing behavior such as the selection of sub-optimal portfolios from the efficient frontier. Such behavior is not consistent with pure wealth maximization and has implications for security pricing and marketing of securities.

- $\quad$ Accepting market efficiency in the context of the impossibility of consistently beating the stock market and rejecting it in the context of bounded rationality would allow the instructor to explore the role of ethics for investment professionals and the role they play in the investment process. For example, selling stocks which have been big losers and buying stocks that have been big winners just before the end of a quarter will not raise the portfolios return and will actually decrease the return due to the trading costs involved. This "Window dressing" behavior displayed by most professional money managers can not be explained by the $\mathrm{EMH}$, however from a behavioral finance perspective, it is clear that the portfolio manager may have an easier time at the client meeting if highly visible "losers" are not in the portfolio.

- $\quad$ Discoveries of severe biases in investor financial decision-making and securities prices are rich areas to explore in the classroom, given that investors typically have straight forward wealth maximizing objectives coupled with considerable advice and ample data for making investment decisions.

In summary, the EMH provides a context for understanding how security prices are determined in the stock market and is based on the assumption that market participants always exhibit rational behavior. According to the 
EMH, when rational investors learn new information, they quickly update their homogeneous beliefs in an unbiased fashion that is consistent with their views of expected returns and risk. The emerging field of BF seeks to understand financial markets in which participants do not always behave in a rational manner. BF has the potential to offer new and useful perspectives on the ways markets actually work and to help us to understand why many individual investors are susceptible to cognitive failures (errors) and psychological biases that cause them to actually lose money in the stock market.

\section{Exhibit A}

S\&P 500, Annualized total return: $1996-2005^{1}$

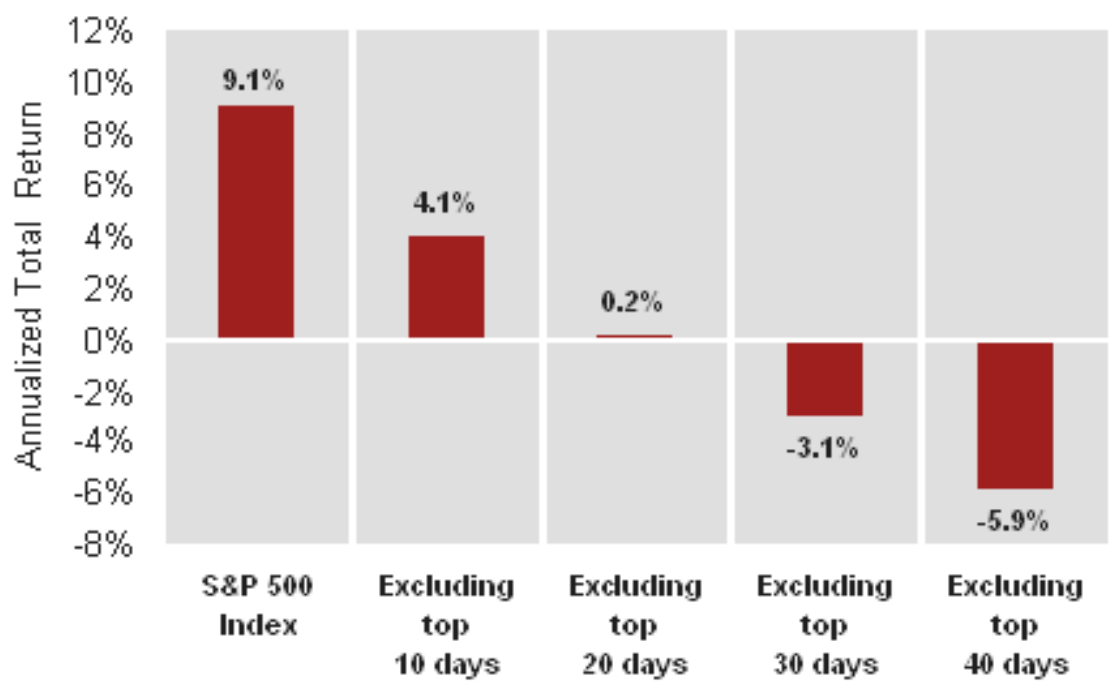

Source: data from Ibbotson Associates, Inc (1)

Exhibit B

Range of S\&P 500 returns, 1,3,5,10,20 year holding periods: $1926-2005^{2}$

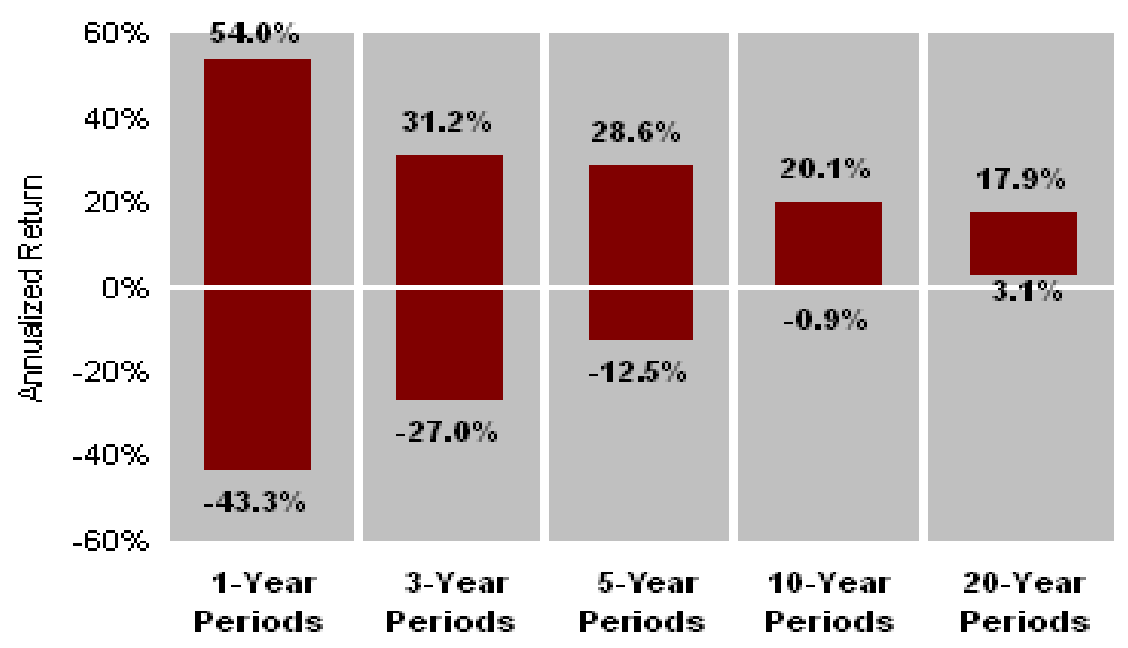

Source: data from Ibbotson Associates, Inc. (2) 
1. Data is annualized based on an average of 252 trading days within a calendar year. The year begins on the first trading day of January and ends on the last trading day of December and daily total return index closing levels were used for the period 1996 through 2005. Total return includes reinvestment of dividends.

2. Every one, three, five, 10 and 20-year rolling calendar period for the S\&P 500 Index was studied from 1926 through 2005, using annual total return data and rolling forward in annual increments. The highest and lowest annualized returns for the specified rolling time periods were chosen to depict the volatility of the market. Total return includes reinvestment of dividends.

\section{REFERENCES}

1. Barberis, Nicholas and Richard Thaler, (2003), A Survey of Behavioral Finance, Handbook of the Economics of Finance, North Holland, Amsterdam.

2. $\quad$ Barberis, N., Huang, M., and Santos, T. (2001) Prospect Theory and Asset Prices (June 1999). Center for Research in Security Prices (CRSP) Working Paper No. 494

3. Baron, J. (2000). Thinking and deciding ( $3^{\text {rd }}$ Edition). New York, NY Cambridge University Press.

4. Bishop, Michael A, and Trout, J.D., (2004) Epistemology and the Psychology of Human Judgement, New York: Oxford University Press.

5. Bossaerts, Peter. The Paradox of Asset Pricing, Princeton University Press, (2001), Princeton, N.J.

6. Debondt and Thaler, (1994), Financial Decision Making in Markets and Firms: A behavioral Perspective Working Paper \#4477, National Bureau of Economic Research, Inc. Cambridge, MA.

7. Fama, Eugene F. (1970), Efficient Capital Markets: A Review of Theory and Empirical Works, Journal of Finance 25: 383-417

8. Fama, Eugene F. and Kenneth R. French, (1996), Multifactor Explanations of Asset Pricing Anomalies Journal of Finance, 51, No. 1, March 55-84.

9. Fama, Eugene F. and Kenneth R. French, (1995), Size and Book-to-Market Factors in Earnings and Returns, Journal of Finance, 50 No. 1 March 131-155.

10. French, Kenneth, (1980), Stock Returns and the Weekend Effect, Journal of Financial Economics 8, 55-69.

11. Hirshleifer, David, (2001), Investor Psychology and Asset Pricing, Journal of Finance 56, 1533-1567

12. Kahneman, D., Slovic, P,. and P.K. Tversjy, (1982) Judgment under Uncertainty: Heuristics and Biases, Cambridge University Press Cambridge.

13. Lakonishok, Josef, Andrei Shleifer, and Robert Vishny, (1994), Contrarian's Investment, Explorations, and Risk, Journal of Finance, Vol 49, no. 5 December, 1541-1578.

14. Mackay, Charles, The Crowd by Gustave Le Bon and Extraordinary Popular Delusions and the Madness of Crowds

15. Malkiel, B. (1990) A Random Walk down Wall Street, Princeton Press, Norton Press, NY, NY

16. Olean, T. (1998) Are investors reluctant to realize their losses? Journal of Finance LIII(5)

17. $\quad$ Olean, T. (1999) Do investors trade too much? American Economic Review

18. Plous, S. (1993) The Psychology of Judgment and Decision Making: McGraw Hill, New York,

19. Ritter, Jay (March 1991), The Long-Run Performance of Initial Public Offerings, Journal of Finance,

20. Shefrin, Hersh, (1999), Beyond Fear and Greed: Understanding Behavior Finance and the Psychology of Investing. Behavioral Corporate Finance, Boston, MA Harvard Press

21. (1994), Behavioral CAPM Theory. Journal of Financial and Quantitative Analysis, Vol. 29 no. 3 (Sept) 323-349

22. Shiller, Robert J., (2000), Irrational Exuberance, Princeton University Press, Princeton, N.J.

23. Smith, Vernon L (1991), Rational Choice: The Contrast Between Economics and Psychology, Journal of Political Economy, Vol. 99 (August), pp 877-97.

24. (1994), Economics in the Laboratory, Journal of Economic Perspectives, Vol. 8 (Winter), pp 11331.

25. Thaler, R. (1999) Mental Accounting Errors Journal of Behavioral Decision Making 12 (3), (1999): 183206.

26. Tversky, A. and Daniel Kahneman, (1986), Rational Choice and the Framing of Decisions, Journal of Business, Vol. 59.

27. Tversky, A. and Daniel Kahneman, (1979), Prospect Theory: An Analysis of Decision Making Under Risk, Econometrica, Vol. 47. 263-291 
28. Tversky, A and Kahneman, D (1992) Advances in prospect theory: cumulative representation 192. 12, Economy Quarterly.

29. Tversky, A. and Kahneman, D. (1981) The Framing of Decisions and the Psychology of Choice. Cambridge, Cambridge University Press, 1982

30. Tversky, A. and Kahneman, D. (1991). Loss Aversion in Riskless Choice: A Reference Dependent Model. Quarterly Journal of Economics 106, 1039-1061.

\section{TEACHING NOTE}

Albeit there is widespread acceptance of the EMH, there is pervasive skepticism and a general lack of understanding of Behavior Finance. This classroom experiment imparts an appreciation for the effects of non rational behavior and conveys a deeper appreciation for efficiency of prices in the market. Students observe first-hand how the lack of rationality on the part of fellow students affects the optimal choice. Moreover, students see how informational efficiency of prices can be impeded by non rational behavior of noise traders.

Behavioral or non-rational investor perceptions have always affected the stock market equilibrium. The current theoretical models and theories for understanding the stock market and the investment processes are flawed in that they have not acknowledged that irrational and emotional human behavior serves a primary role in the markets, just as it has in every other component of our lives. Some BF researchers now use the term "bounded rationality" to suggest that investors are usually rational but not always defined or bound by purely rational concerns. As a result financial markets are seldom in equilibrium due to the human, or non-rational, marginal investor participating in the stock market. This would help to explain the large trading volume in the financial markets that we have become accustomed to.

An interesting classroom experiment, that is simple and quick to run, and can be used to demonstrate the concept of irrational behavior (Noise traders) and the EMH can elicit lively class discussion. The rules are very simple. Invite the students in your class to write down a number between 0 and 100 without showing the number to anyone else. The instructor will collect the pieces of paper and calculate the class average of these numbers. Next, the instructor will divide the class average by 2 . The person who wrote down a number closest to this final value will win.

Suppose students in this game select numbers purely at random. The average guess will therefore be about 50. Recognizing this, and remembering that the rules of the game dictate that the average guess will be cut in half, you might guess 25 . However, if everyone is rational, the class average divided by 2 should be $25 / 2=12.5$.

Conduct the experiment a second time and the instructor can clearly demonstrate how efficient the market for number picking is. Students that think a bit more, will realize that everyone else playing the game understand this too. Suppose everyone guesses 12.5. In that case, the average guess divided by two will be 6 .

Run the experiment a third time. Should students choose 6 or 7 as their guess? Not necessarily, because all the other players should start to recognize this pattern. It turns out that the optimal guess is the minimum number allowed, in this case 1 . However, a problem arises if not every player logically thinks this far ahead. Some players may forget about incorporating the possible actions of others in their guesses. Essentially, players who guess any number other than 1 in this game are analogous to noise traders in the market. They do not understand that the rational guess is 1 , and because the noise traders choose other numbers, the result is that the winning number in the game will not in fact be 1 . The really interesting result of the experiment is how the market participants use new information to adjust their guesses to the rational value. Within three iterations, the two values will tend to equate one to the other. It would appear that the market for numbers is extremely informationaly efficient. However, the fundamental question is whether classmates (investors) can beat the market (experiment). The answer would appear to be no. The stock market is made up of two types of traders, namely, information traders and noise traders. Information traders are the investors envisioned by the standard EMH paradigm; free of cognitive errors and have clearly defined mean-variance preferences. Noise traders populate BF; they have a propensity to commit cognitive errors in a systematic manner and are not bound by clearly defined mean variance criterion. 


\section{CLASS DISCUSSION}

"Securities prices are highly correlated with intrinsic value, but sometimes diverge to a significant degree for an extended period of time." (Thaler 1994) - How does this relate to the experiment? If some students still do not behave rationally, how does this change the strategy of a rational player?

Warren Buffet once remarked that "if markets were efficient, I would be a beggar on the street corner with a tin cup". How can you explain his investment success in the context of the EMH?

John M. Keyes once said that picking stocks was like picking the winner of a beauty pageant. If you are rewarded for picking the winner you should not necessarily choose the contestant that you feel has the most talent or looks, but the one the majority of other judges will pick. How does this relate to the experiment?

Modern investment theory is based on the following assumption of investor behavior: all market participants have the goal of utility maximization, i.e., obtained wealth. One of the basic assumptions of the rational investor is that they will always attempt to maximize their wealth. The marginal utility of wealth is always positive. Will rational people always act in their best interest?

\section{NOTES}


NOTES 